\title{
edmetic
}

Revista de Educación Mediática y TIC

\section{Propuesta metodológica para la integración didáctica de la realidad aumentada en Educación Infantil}

\author{
Methodological proposal for the didactic integration of \\ augmented reality in Early Childhood Education
}

\author{
Lourdes Villalustre Martínez ${ }^{1}$
}

Fecha de recepción: 21/01/2019; Fecha de revisión: 28/05/2019; Fecha de aceptación: $31 / 05 / 2019$.

Cómo citar este artículo:

Villalustre Martínez, L. (2020). Propuesta metodológica para la interación didáctica de la realidad aumentada en Educación Infantil. EDMETIC, Revista de Educación Mediática y TIC, 9(1), 170-187. doi: https://doi.org/10.21071/edmetic.v9i1.11569

Autor de Correspondencia: villalustrelourdes@uniovi.es

\begin{abstract}
Resumen:
Los dispositivos multitáctiles posibilitan el acceso e interacción con recursos enriquecidos con realidad aumentada. Dada su flexibilidad y adaptabilidad pueden ser utilizados en diferentes contextos para optimar los procesos formativos. En esta línea, en el marco de la asignatura de Tecnologías de la Información y Comunicación aplicadas a la Educación Infantil se llevó a cabo una experiencia formativa centrada en la utilización de la realidad aumentada. Así, los 119 futuros maestros que la cursaron diseñaron una propuesta metodológica mediante la creación de recursos con realidad aumentada para organizar acciones formativas estrcuturadas en tres rincones, en los que se abordaban contenidos asociados a ciencias, lengua y matemáticas. Para llevar a cabo esta experiencia se presentó un conjunto de pautas para articular las propuestas educativas. Tras su desarrollo, se solicitó a los estudiantes que valorasen como futuros maestros/as el potencial didáctico de esta tecnología. Para ello, dieron respuesta a siete ítems creados al efecto. Constatando que éstos consideran que la realidad aumentada es muy motivadora y atrayante para abordar, sobre todo, contenidos lingüísticos. Si bien manifiestan su dificultad para abordar contenidos matemáticos y científicos, dadas las limitaciones técnicas que declaran poseer para generar recursos innovadores.
\end{abstract}

Palabras clave: Realidad aumentada; Rincones; Educación infantil; Metodología.

\begin{abstract}
:
Mobile technologies enable access and interaction with enriched resources with augmented reality. Given their flexibility and adaptability, they can be used in different contexts to optimize training processes. In this line, in the subject of Information and Communication Technologies applied to Early Childhood Education, a training experience focused on the use of augmented reality was carried out. Thus, the 119 future teachers who studied it designed a meotodological proposal through the creation of augmented reality resources to organize training actions in three corners, in which contents of science, language and mathematics were addressed. To carry out this experience, a set of guidelines was presented to articulate the educational proposals. After its development, students were asked to evaluate the didactic potential of this technology as future teachers. For this, they responded to seven items created for that purpose.
\end{abstract}

\footnotetext{
I Universidad de Oviedo (España), villalustrelourdes@uniovi.es; (Dhttp://orcid.org/0000-0002-5427-5355.
} 
Noting that they consider that augmented reality is very motivating and attractive to work, especially linguistic content. However, they manifest their difficulty in addressing mathematical and scientific content, given the technical limitations they claim to possess to generate innovative resources.

Key Words: Augmented reality; Corners; Children's education; Methodology. 


\section{INTRODUCCIÓN}

La utilización de las nuevas tecnologías en las aulas obliga a efectuar un cambio en las prácticas educativas, convirtiéndose en un elemento importante de cualquier proceso educativo e innovador (Danneels, 2004; Cabero, 2015). De forma pareja a los avances tecnológicos se han ido produciendo innovaciones para adaptar las nuevas herramientas a las necesidades de los discentes. En este contexto, el profesorado deberá ser capaz de crear planes de trabajo para su incorporación en el aula haciendo un uso constructivo de las nuevas tecnologías.

Desde esta perspectiva los procesos de innovación, según establece Mangelsdorf (2008), modifican los paradigmas tradicionales educativos en tanto que impactan, por un lado, en los procesos de enseñanza que aplican los docentes, y por otro, en las estrategias de aprendizaje que utilizan los estudiantes. Así, la experiencia e implicación del profesorado se constituye en el elemento clave para la innovación, pues de ellos va a depender el desarrollo de propuestas educativas que favorezcan la integración curricular de los nuevos avances tecnológicos (Cebrián, 2003; Fidalgo, 2016).

Todo ello exige planificar nuevas estrategias didácticas más flexibles capaces de promover experiencias innovadoras en los procesos formativos apoyados en el uso de las Tecnologías de la Información y Comunicación (TIC). En este contexto, la Realidad Aumentada (RA) ofrece numerosas oportunidades. Ésta combina información física y digital en un mismo espacio para obtener mayor información del entorno que nos rodea (De la Horra, 2017). De igual modo, posibilita la interacción en tiempo real entre los usuarios y los contenidos aumentados creando una realidad mixta a través de un registro tridimensional generado a partir de imágenes reales, capaces de añadir nueva información visual a la ya existente.

Con ella, se amplia el conocimiento y la percepción del mundo físico con imágenes tridimensionales, sonidos, animaciones, etc. para ampliar la realidad con contenidos interactivos y digitales (Lee, 2012; Carbonell y Bermejo, 2017). La RA posee numerosas aplicaciones en diferentes ámbitos, entre ellos el educativo, dado su potencial para favorecer el aprendizaje significativo (Billinghurst, 2012). De igual modo, existen diferentes niveles de RA, según establecen Cawood y Fiala (2008): 
- Nivel 0: Hiperenlaces en el mundo físico; mediante la utilización de códigos QR (Quick Response Barcode) como activadores a través de smartphone y tablets.

- Nivel I: Realidad aumentada basada en marcadores; empleando los marcadores como elementos activadores mediante la superposición de modelos 3D.

- Nivel II: Realidad aumentada markerless; en este caso, se utilizan imágenes y objetos como activadores.

- Nivel III: Visión aumentada; mediante la utilización de gafas específicas (Google Project Glass) o de Lentillas biónicas.

La portabilidad que esta tecnología tiene asociada a través del uso de los dispositivos móviles tiene implicaciones en los procesos formativos al posibilitar que el aprendizaje tenga lugar en cualquier momento y lugar (Burbules, 2012; Villalustre, 2016). Así, a través de la RA se promueven nuevos contextos y estrategias que tienen un impacto sobre el aprendizaje. Teniendo esto en cuenta, han sido varias las experiencias que se han llevado a cabo en diferentes contextos y niveles educativos con el uso de esta tecnología (Garrett, Anthony y Jackson, 2018; Moreno y Leiva, 2017). La RA genera nuevas oportunidades, no sólo para los estudiantes al posibilitar un rol más activo, sino también para los docentes conformando una nueva ecología de la enseñanza ligada no sólo a las potencialidades de las herramientas digitales sino también a los factores motivacionales que propician.

En esencia, el aprendizaje mediado por la RA permite relacionar las metas de aprendizaje con los contextos y los propósitos educativos ligados a la experiencia, tal y como apuntan Pimmer, Mateescu y Gröhbiel (2016). Por su parte, Cattaneo, Motta y Gurtner (2015) destacan los beneficios de su utilización en las aulas desde el punto de vista de la usabilidad, la efectividad y la satisfacción de los estudiantes.

La realidad aumentada proporciona a los estudiantes una capa adicional y multimedia de experiencias interactivas que añaden un flujo simultáneo de información que pueden generar en actividades formativas 
enriquecedoras (Hsu, Chiou, Tseng y Hwang, 2016), siendo un recurso enormemente poderoso para potenciar la adquisición y consolidación de aprendizajes de diversa índole (Ibáñez y Delgado, 2018). El profesorado ante este nuevo ecosistema requiere de nuevas estrategias que integren y aprovechen las oportunidades que brindan las tecnologías móviles (Hung, Hwang, Lee, Wu, Vogel, Milrad y Johansson, 2014). Así, haciendo uso de esta tecnología se solicita a la futuros maestros/as de Educación Infantil que diseñen acciones formativas mediante la creación de diversos recursos con RA para planificar dentro del aula tres rincones aumentados.

\section{RINCONES AUMENTADOS EN EDUCACIÓN INFANTIL}

\subsection{Objetivos de la experiencia desarrollada}

Desde la asignatura de TIC aplicadas a la Educación del Grado de Maestro en Educación Infantil se llevó a cabo una experiencia centrada en el diseño y programación de actividades formativas basadas en la utilización de la RA. Para ello, los objetivos que se perseguían fueron:

- Acercar a los estudiantes universitarios nuevos recursos tecnológicos, en concreto la RA, para su explotación didáctica.

- Diseñar por parte de los estudiantes recursos didácticos con RA para abordar contenidos asociados a la ciencia, las matemáticas y la lengua.

\subsection{Metodología potenciada con la innovación planteada}

En la etapa de Educación Infantil se hace uso de numerosas estrategias metodologías para potenciar aprendizajes de diversa índole. Si bien, el empleo de rincones esta ampliamente extentido en esta etapa educativa, dada la flexibilidad y adaptabilidad que posibilita para potenciar tanto el aprendizaje individual como aquel desarrollado en pequeños grupos (Sensat, 2006; Leguia y Vidal, 1991). El trabajo por rincones es una estrategia que pretende dar respuesta a las diferentes necesidades del alumnado en función de sus preferencias cognitivas y ritmos de aprendizaje.

La utilización de los rincones como estrategia potencia la autonomía de los estudiantes, puesto que éstos deben organizarse, planificar su trabajo, saber qué quieren aprender y qué camino pueden utilizar para conseguirlo 
(Gómez-Montilla y Ruiz-Gallardo, 2016). De igual modo, propician la exploración y la resolución de problemas, aproximando al alumnado a un aprendizaje por descubrimiento (Riera, Ferrer \& Ribas, 2018). Por todo ello, se planteo a los futuros maestros de Educación Infantil que organizasen diferentes rincones para abordar contenidos asociados a los ámbitos de lengua, matemáticas y conocimiento del medio. Estos espacios se estructuraban a partir de la propuesta de diferentes actividades mediante la utilización de recursos de RA, con el fin, no sólo de motivar a los niños/as con el uso de esta nueva tecnología sino también de propiciar la adquisición de nuevos aprendizajes.

\subsection{Fases de ejecución de la experiencia innovadora}

La acción formativa se desarrolló en el marco de la asignatura de TIC aplicadas a la Educación del Grado de Maestro en Educación Infantil, en la que participarón un total de 119 estudiantes universitarios con el fin de diseñar diversos recursos formativos con RA. Para ello, se desarrollaron las siguientes fases:

FASE I: Planificación de la acción formativa. Delimitación de la finalidad y la propuesta de creación de rincones con RA cómo estrategia formativa para educación infantil.

FASE II: Formación en las herramientas RA utilizadas. Se desarrollarón varias sesiones formativas par acercar a los estudiantes universitarios a las herramientas de RA empleadas: Códigos QR, Arcrowd, HP Reveal (antes denominada Aurasma) y Eduloc.

FASE III: Diseño y planificación de los rincones aumentados. Los discentes a lo largo de tres semanas planificarón y organizarón los rincones aumentados, creando y utilizando los recursos de RA necesarios.

\subsection{Herramientas y aplicaciones de RA utilizadas}

Para el diseño de los recursos de RA los estudiantes podían hacer uso de cualquier herramienta. Si bien, se desarrollón cuatro talleres para acercar el manejo de cuatro aplicaciones de RA que se corresponden a los diferentes niveles delimitados por Cawood \& Fiala (2008), a saber: 
- Nivel 0: mediante la utilización de Códigos QR; código de barras bidimensional que puede almacenar diferentes datos codificados. Es el nivel básico y el más sencillo. Existen númerosas aplicaciones y generadores web para su creación. En el taller se utilizó: http://www.codigos-ar.com/generador-de-codigos-ar/; $\quad$ https://es.arcode-generator.com; entre otros.

- Nivel I: a través de la herramienta web Arcrowd2; plataforma web gratuita que permite crear marcadores añadiendo contenidos multimedia e incluso utilizar la galeria de objetos 3D que posee.

- Nivel II: empleando las herramientas HP Reveal ${ }^{3}$ y Eduloc ${ }^{4}$. La primera, posibilita el diseño de recursos en RA empleando cualquier imágen $u$ objeto como activador, mientras que la segunda, se basa en la geolocalización mediante la utilización de dispositivos móviles, que permite crear diferentes itinerarios a modo de juego.

A partir de estas herramientas y aplicaciones de RA los estudiantes universitarios crearón recursos y actividades formativas, los cuales formarón parte de los tres rincones planificados. Algunos de ellos se muestran en el siguiente apartado.

\subsection{Presentación de los recursos RA creados para su utilización en los rincones}

Los futuros maestros/as de Educación Infantil, agrupados en equipos de 3/4 personas, desarrollaron actividades y recursos con RA para gestionar tres rincones dentro del aula de educación infantil: 1) el rincón de la ciencia aumentada; 2) rincón de las matemáticas aumentadas, y 3) el rincón del lenguaje aumentado. Así, los estudiantes debían planificar y organizar acciones formativas para los tres rincones, creando recursos de RA con las herramientas proporcionadas (Códigos QR, Arcrowd, HP Reveal y Eduloc).

De este modo, se diseñarón un total de 38 recursos aumentados para abordar contenidos en estos tres ámbitos, concretamente: 15 de lengua, para abordar contenidos relacionados a la iniciación a la lectura y la adquisición de vocabulario; 13 recursos de matemáticas, destinados a conocer la seriación y

\footnotetext{
2 http://arcrowd.com

${ }^{3}$ https://studio.hpreveal.com/landing

${ }^{4}$ http://www.eduloc.net/es
} 
operaciones matemáticas básicas; y 10 de ciencias, orientados sobre todo al conocimiento del medio ambiente y el mundo animal.

Para ello, los estudiantes utilizarón diferentes herramientas atendiendo a los niveles de RA delimitados por Cawood \& Fiala (2008), más especificamente, crearón 18 recursos a través de códigos QR (Nivel 0); 9 mediante la creación de marcadores con la herramienta Arcrowd (Nivel I); y por ultimo, 11 empleando las herramientas HP Reveal y Eduloc (Nivel II). Desde aquí, se presentan algunos de ellos:

a. Rincón de la ciencia aumentada

Los futuros maestros/as diseñaron recursos y actividades mediante la utilización de códigos $Q R$, como nivel más básico de RA, entre ellos, la creación de "la oca de las ciencias", donde los discentes elaboraron un tablero digital partiendo del popular juego de la oca, las cuales eran sustituidas por códigos QR que contenían diferentes preguntas que debían ser resueltas para poder continuar en el juego.

Figura 1. Recurso creado por los estudiantes universitarios con códigos QR

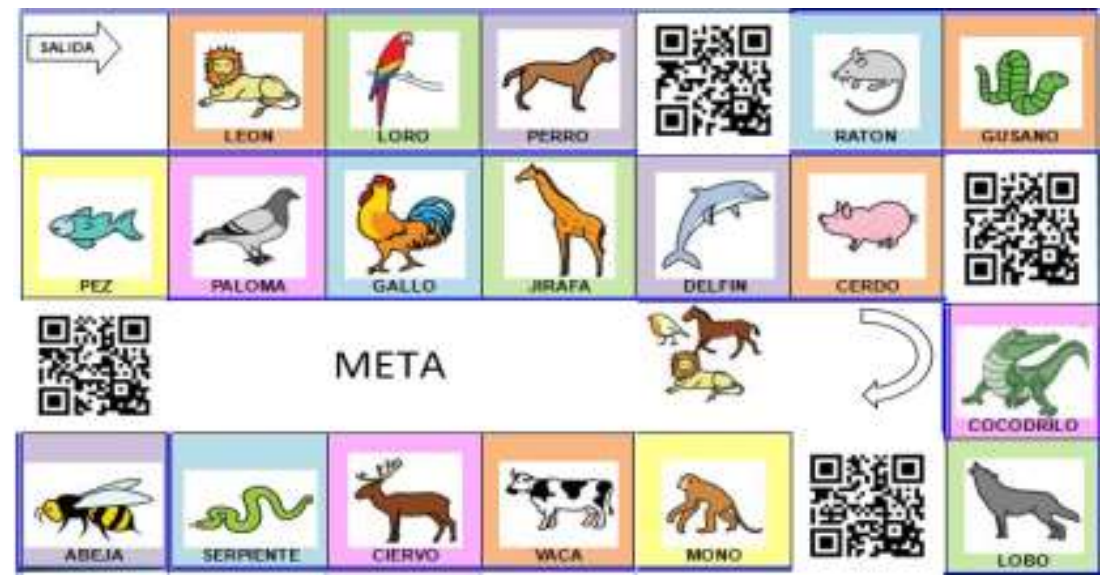

De igual modo, se emplearon los códigos QR para abordar contenidos tanto de matemáticas como de ciencias, por ejemplo la utilización de códigos QR para la identificación de las distintas partes del cuerpo humano.

\section{b. Rincón de las matemáticas aumentadas}

Por otro lado, utilizaron marcadores como activadores de la RA en actividades destinadas a abordar todo tipo de contenidos, como por ejemplo "las cartas mágicas" que escondían la solución a pequeñas operaciones matemáticas. 
Figura 2. Recurso creado por los estudiantes universitarios con marcadores
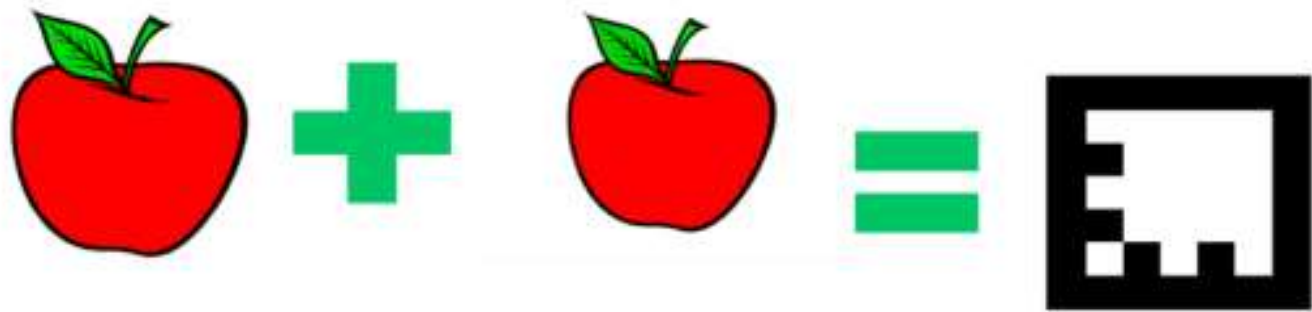

En ellas, se les mostraba a los niños/as pequeñas operaciones muy básicas, y adaptadas a su nivel educativo, donde la solución se encontraba oculta tras un marcador que debían escanear con la aplicación Arcrowd, mostrándose, en este ejemplo, un pequeño vídeo animado con el número que correspondía.

c. Rincón de la lengua aumentada

También se utilizó el programa HP Reveal (antes Aurasma) para emplear diversas imágenes como activadoras, centrando algunas de las actividades creadas por los estudiantes en la elaboración de pequeños relatos de producción propia e incluso también algunas adaptaciones como la efectuada del libro "El monstruo de los colores" de Anna Llenas.

Figura 3. Utilización del libro "El monstruo de los colores" para crear recursos aumentados con HP Reveal
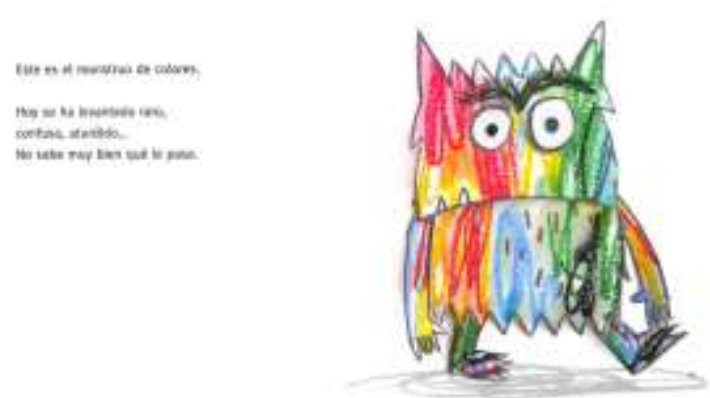

Por otro lado, utilizando el programa Eduloc los futuros maestros/as de educación infantil planificaron un itinerario, donde la geolocalización y las coordenadas GPS cobraban protagonismo. Pues debían seleccionar diferentes lugares de interés para diseñar un recorrido destinado a niños/as de educación infantil y abordar diversos contenidos. 
Figura 4. Itinerario creado por los estudiantes universitarios con Eduloc

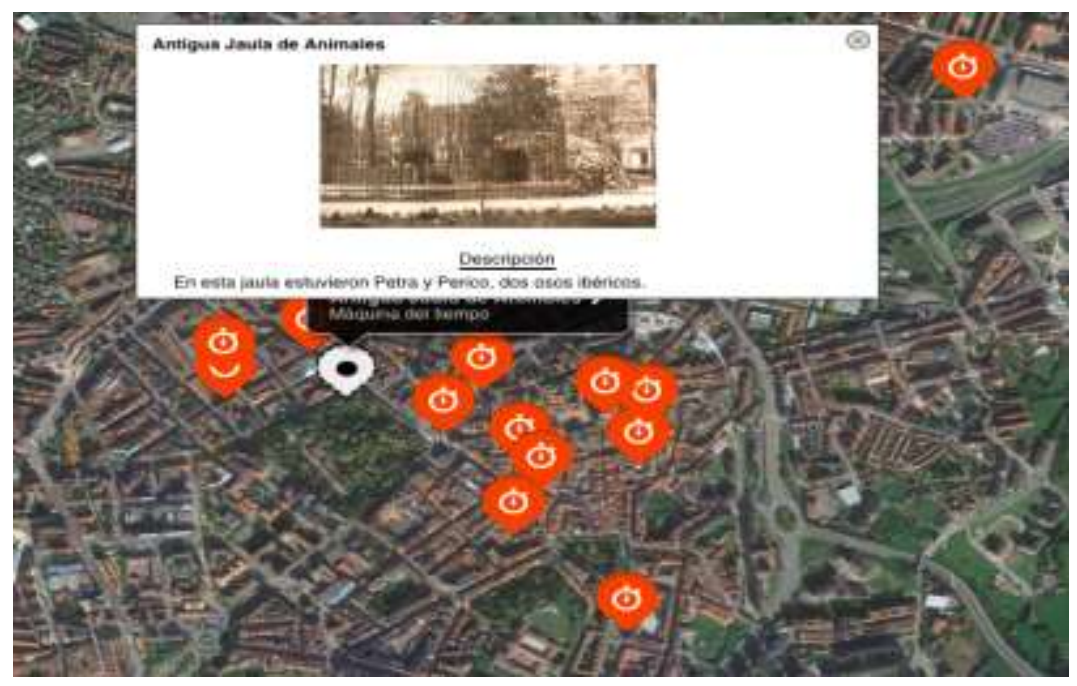

Además de la planificación y organización de los recursos de RA en función de los tres rincones, los futuros maestros/as de educación infantil debían identificar los elementos didácticos que guiasen el proceso formativo, estableciendo los objetivos a alcanzar, los contenidos a abordar, así como la evaluación, a través de rúbricas creadas por ellos. Así, la guía debía contener, al menos, los siguientes elementos:

- Los objetivos didácticos que guiaron el diseño de los recursos.

- Los contenidos que se abordan en ellos.

- Las competencias que se desarrollaban.

- Las actividades formativas para potenciar la colaboración.

- La evaluación, a través de rúbricas de evaluación creadas por ellos.

\subsection{Organización de los rincones aumentados}

Los estudiantes universitarios además de diseñar actividades y recursos con RA debían establecer la estructura organizativa de cada uno de rincones dentro del aula de Educación Infantil, teniendo en cuenta su distribución para hacer posible el desarrollo del trabajo, tanto de manera individual como en pequeños grupos. De este modo, debían planificar:

- La distribución de los recursos tecnológicos dentro del aula para que fuera posible el desarrollo simultáneo de diferentes actividades en los diversos rincones temáticos. 
- Programación de las actividades para su adecuación a los contenidos recogidos en el curriculum de esta etapa educativa.

- Planificación de los rincones con el fin de compaginar aquellas actividades con RA que los niños puedan desarrollar de manera autónoma (previa explicación de su funcionamiento) con otras que requieran de una mayor presencia del docente.

- La duración de las sesiones, generalmente, entre media hora y una hora y media. Así como la periodicidad en la que se utilizarán los rincones aumentados.

\section{Valoración de los estudiantes sobre el potencial de la RA cómo recurso formativo en la etapa de Educación Infantil}

\subsection{Objetivo}

Tras el desarrollo de la experiencia formativa se pretende:

- Conocer la valoración de los estudiantes, desde su condición de futuros maestros/as, sobre el potencial de la RA como recurso formativo a través de rincones en las aulas de Educación Infantil.

\subsection{Muestra}

La muestra de estudio estaba constituida por 119 estudiantes universitarios que cursarón la asignatura de TIC aplicadas a la Educación. De los cuales, el 90\% de los mismos eran mujeres, mientras que el $10 \%$ restante eran hombres. Constatando la predominancia de presencia femenina.

\subsection{Instrumento}

Para conocer las valoraciones de los discentes se crea un cuestionario de respuesta anónima formado por 7 ítems. 6 de ellos creados a través de una escala tipo Likert con cuatro opciones de respuesta (donde 1 equivale a totalmente en desacuerdo y 4 totalmente de acuerdo) y una pregunta abierta para que matizarán lo que considerasen oportuno. Los seis ítems se agruparón en dos bloques destinados a conocer: 1) las valoraciones de los discentes sobre el potencial que posee la RA como recurso formativo; y 2) sus consideraciones sobre la capacidad de la RA para abordar contenidos científicos, matemáticos y lingüísticos. 


\subsection{Metodología}

Una vez que los estudiantes universitarios crearón los recursos de RA y organizarón las actividades a través de rincones, se les solicitó que valorasen el potencial de la RA. Así, se desarrolla un estudio cuantitativo descriptivo basado en el estudio de casos, para conocer las valoraciones de los estudiantes universitarios acerca de las posibilidades y potencialidades de la RA como recurso formativo en la etapa de Educación de Infantil.

\section{Resultados}

\subsection{Potencial de la RA como recurso formativo}

El primer primer bloque de preguntas estaba formado por tres ítems, destinados a conocer las impresiones de los futuros maestros de Educación Infantil en relación al potencial que posee la RA como recurso formativo en las aulas de esta etapa educativa (Tabla 1).

Tabla 1. Distribución porcentual de las valoraciones de los estudiantes en relación al potencial de la RA como recurso formativo

\begin{tabular}{|c|c|c|c|c|}
\hline Items & $\begin{array}{l}\text { 1: Totalmente en } \\
\text { desacuerdo }\end{array}$ & $\begin{array}{c}\text { 2: En } \\
\text { desacuerdo }\end{array}$ & $\begin{array}{c}\text { 3: De } \\
\text { acuerdo }\end{array}$ & $\begin{array}{l}\text { 4: Totalmente } \\
\text { de acuerdo }\end{array}$ \\
\hline $\begin{array}{l}\text { Considero que la RA } \\
\text { posee numerosas } \\
\text { posibilidades para } \\
\text { favorecer el } \\
\text { aprendizaje en Ed. } \\
\text { Infantil }\end{array}$ & $0 \%$ & $9,2 \%$ & $51,3 \%$ & $39,5 \%$ \\
\hline $\begin{array}{l}\text { Considero que la RA } \\
\text { es muy atractiva y } \\
\text { motivadora para los } \\
\text { niños/as de Ed. } \\
\text { Infantil }\end{array}$ & $0 \%$ & $4,2 \%$ & $51,2 \%$ & $44,6 \%$ \\
\hline $\begin{array}{l}\text { Creo que la RA es } \\
\text { muy versátil y que } \\
\text { podría ser utilizada } \\
\text { para abordar } \\
\text { cualquier tipo de } \\
\text { contenido en Ed. } \\
\text { Infantil }\end{array}$ & $1,6 \%$ & $8,4 \%$ & $68 \%$ & $22 \%$ \\
\hline
\end{tabular}

Así, como se puede apreciar en la tabla 1, algo más de la mitad de los futuros maestros consideran que la RA posee numerosas posibilidades para favorecer el aprendizaje en los niños/as de Educación Infantil, destacando a 
través de la pregunta abierta, el potencial de la RA para despertar la implicación e interés de los más pequeños, pues «[...]hace visible cosas que están ocultas a simple vista y eso es algo muy mágico para los niños) (RES 16). En esta misma línea, algo más del $95 \%$ (51,2\%, de acuerdo y 44,6\%, totalmente de acuerdo) de los estudiantes universitarios consideran que éste nuevo recurso tecnológico es muy motivor para esta etapa educativa. De igual manera, un $68 \%$ está de acuerdo en afirmar que la RA es un recurso muy versátil para abordar cualquier tipo de contenido. Si bien, un $10 \% \quad(1,6 \%$, totalmente en desacuerdo y $8,4 \%$, en desacuerdo) declara su desacuerdo y matizan que se ven condicionados por las posibilidades de las herramientas y aplicaciones, pues declaran que «el HP Reveal a veces no funcionaba correctamente, no reconocia las imágenes, y otras veces si» (RES19) "a veces las herramientas fallaban y esto nos genera dudas de si realmente pueden ser utilizadas en clase con niños tan pequeños») (RES32).

\subsection{Potencial de la RA para abordar contenidos científicos, matemáticos y lingüísticos}

En un segundo bloque de cuestiones, formado por tres ítems, se pregunta a los futuros maestros de Educación Infantil su consideración en relación a la capacidad de la RA para abordar los contenidos trabajados en los rincones.

Tabla 2. Distribución porcentual de las valoraciones de los estudiantes en relación al potencial de la RA para abordar contenidos específicos

\begin{tabular}{|c|c|c|c|c|}
\hline Items & $\begin{array}{l}\text { 1: Totalmente en } \\
\text { desacuerdo }\end{array}$ & $\begin{array}{c}\text { 2: En } \\
\text { desacuerdo }\end{array}$ & $\begin{array}{c}\text { 3: De } \\
\text { acuerdo }\end{array}$ & $\begin{array}{l}\text { 4: Totalmente } \\
\text { de acuerdo }\end{array}$ \\
\hline $\begin{array}{l}\text { Considero que la RA es } \\
\text { un buen recurso para } \\
\text { enseñar contenidos } \\
\text { científicos a niños de } \\
\text { Ed. Infantil }\end{array}$ & $0,8 \%$ & $7,6 \%$ & $57,1 \%$ & $34,5 \%$ \\
\hline $\begin{array}{l}\text { Creo que la RA es un } \\
\text { buen aliado para } \\
\text { abordar contenidos } \\
\text { matemáticos con niños } \\
\text { de infantil. }\end{array}$ & $0,8 \%$ & $7,6 \%$ & $65,5 \%$ & $26,1 \%$ \\
\hline $\begin{array}{l}\text { Considero la RA como } \\
\text { un buen recurso para } \\
\text { trabajar la } \\
\text { competencia } \\
\text { lingüística en Ed. } \\
\text { Infantil. }\end{array}$ & $0 \%$ & $8,4 \%$ & $63 \%$ & $28,6 \%$ \\
\hline
\end{tabular}


Como se puede constatar en la Tabla 2, los estudiantes universitarios consideran estar de acuerdo en afirmar que esta tecnología es flexible para abordar contenidos de diversa índole, con porcentajes que superan el $90 \%$ en todos los casos. E inciden en las respuestas abiertas en manifestar «el gran potencial de esta herramienta para acercar a los niños contenidos complejos» (RES9), así como umostrar a los más pequeños animaciones en 3D de contenidos que de otro modo sería más dificil de abordan» (RES24). Si bien, su desacuerdo es algo más acentuado en el caso de abordar contenidos relacionados con las matemáticas y las ciencias. En este sentido, en la pregunta abierta, manifiestan las dificutades encontradas para crear recursos y organizar actividades con RA para estas áreas, ya que «nos hubiera gustado poder incluir más imágenes en 3D y animaciones para explicar conceptos científicos, pero no sabemos crearlo y tampoco los hemos encontrado» (RES28); «crear materiales con realidad aumentada para matemáticas no ha sido fácil porque no queríamos hacerlo muy difícil ya que son niños de infantil y no se nos ocurrían ideası (RES11).

\section{DISCUSIÓN/CONCLUSIONES}

La RA está penetrando en el ámbito educativo potenciando el desarrollo de nuevas metodologías que implican novedosas formas de acceso y procesamiento de la información a través de imágenes virtuales, de visores especiales, etc. Por ello, en el presente trabajo se ha utilizado la RA para favorecer el aprendizaje mediante la creación de rincones aumentados. La práctica formativa descrita ha supuesto una experiencia innovadora de primer orden para los futuros maestros de Educación Infantil, pues para algunos se trataba de un primer contacto con estas tecnologías emergentes. No obstante, para la mayoría la expereincia formativa fue valorada muy positivamente.

Así, los estudiantes universitarios destacan el potencial didáctico de estos recursos para configurar una propuesta metodológica basada en la creación de rincones. En ella, la RA adquiere protagonismo para promover la adquisición de nuevos aprendizajes. En esta misma línea, los trabajos desarrollados por Wu, Lee, Chang y Liang (2013) refuerzan la necesidad de 
introducir estas tecnologías en la formación de los futuros maestros para potenciar su integración didáctica en las aulas de una manera inclusiva y dinámica, más allá de un uso instrumental.

Asímismo, manifestaron un gran interés y motivación hacia la tarea propuesta, tal y como se pudo observar a lo largo de su desarrollo, en consonancia con los resultados obtenidos por Cózar, Del Valle, Hernández y Hernández (2015). De igual modo, se constató cómo los discentes participaron activamente y percibieron la utilidad y las posibilidades que ofrece la RA para planificar y organizar los rincones.

Consideran que esta tecnología es altamente motivadora para los niños y niñas de Educación Infantil, y que contribuye a potenciar la implicación de los más pequeños hacia los contenidos formativos abordados, de acuerdo a los estudios desarrollados por Fonseca, Redondo y Valls (2016). Si bien, manifiestan SU dificultad para utilizar la RA en determinados contenidos, en especial, en matemáticas y ciencias, pues les entraña una dificultad añadida crear recursos innovadores y atractivos para abordar estos ámbitos.

En este sentido, se ha podido percibir las dificultades que poseen los estudiantes para generar ideas innovadoras y creativas de integración curricular de la RA en un proceso formativo. Así, se ha tenido que realizar un gran esfuerzo para promover entre los estudiantes el diseño de recursos atractivos, capaces no sólo de favorecer el aprendizaje sino también de fomentar la imaginación. Ello es, por tanto, uno de los principales retos a los que se ha hecho frente y del que todavía queda camino por recorrer.

Con todo, los estudiantes valoraron la experiencia llevada a cabo, considerándola muy positiva cómo futuros maestros/as, pues declararon desconocer el potencial de la RA para favorecer el aprendizaje y la adquisición de conocimientos de diversa índole. Manifestando percibir la capacidad de estos nuevos recursos para despertar la motivación y el interés del alumnado de Educación Infantil.

\section{REFERENCIAS}

BILLINGHURST, M. (2012). Augmented Reality in the Classroom. Computer, 45(7), 56-63. doi:10.1109/MC.2012.111 Google Schoiar 
BURBULES, N.C. (2012). Ubiquitous Learning and the Future of Teaching. Encounters, 13, 3-14. Google Scholar

CABERO, J. (2015). Reflexiones educativas sobre las tecnologías de la información y la comunicación (TIC). Tecnología, Ciencia y Educación, 1, 19-27. Google Scholar

CARBONELL, C., y BERMEJO, L. A. (2017). Landscape interpretation with augmented reality and maps to improve spatial orientation skill. Journal of Geography in Higher Education, 41(1), 119-133. doi: https://doi.org/10.1080/03098265.2016.1260530 Google Scholar

CAWOOD S., y FIALA M. (2008). Augmented Reality: A Practical Guide. Denver: Pragmatic Bookshelf.

CATTANEO, A. A., MOTTA, E., y GURTNER, J. L. (2015). Evaluating a Mobile and Online System for Apprentices' Learning Documentation in Vocational Education: Usability, Effectiveness and Satisfaction. International Journal of Mobile and Blended Learning (IJMBL), 7(3), 40-58. doi: 10.4018/IJMBL.2015070103 Google Scholar

CEBRIÁN, M. (2003). Enseñanza virtual para la innovación universitaria. Madrid: Editorial Narcea.

CÓZAR, R., DEL VALLE, M., HERNÁNDEZ J., y HERNÁNDEZ, J. (2015). Tecnologías emergentes para la enseñanza de las Ciencias Sociales. Una experiencia con el uso de Realidad Aumentada en la formación inicial de maestros. Digital Education Review, 27, 138-153.

DANNEELS, E. (2004). Disruptive Technology Reconsidered: A Critique and Research Agenda. Journal of Product Innovation Management, 21 (4), 246-258. doi: https://doi.org/10.1111/j.0737-6782.2004.00076.x Google Scholar

DE LA HORRA, I. (2017). Realidad aumentada, una revolución educativa. EDMETIC, Revista de Educación Mediática y TIC, 6(1), 9-22. doi: https://doi.org/10.21071/edmetic.v6i1.5762 Google Schoiar

FIDALGO, Á. (2016). La innovación docente y los estudiantes. La cuestión universitaria, 7, 84-91. Gaogle Scholar

FONSECA, D., REDONDO, E., y VALLS, F. (2016). Motivación y mejora académica utilizando realidad aumentada para el estudio de modelos 
tridimensionales arquitectónicos. Education in the Knowledge Society (EKS), 17(1), 45-64. doi: 10.14201/eks20161714564 Google Scholar

GARRETT, B. M., ANTHONY, J., y JACKSON, C. (2018). Using mobile augmented reality to enhance health professional practice education. Current Issues in Emerging eLearning, 4 (1), article 10.

GÓMEZ-MOTILLA, C., y RUIZ-GALLARDO, J. R. (2016). El rincón de la ciencia y la actitud hacia las ciencias en educación infantil. Revista Eureka sobre Enseñanza y Divulgación de las Ciencias, 13(3), 643-666. doi: 10498/18503. Gaogle Scholar

IBÁÑEZ, M. B., y DELGADO-KLOOS, C. (2018). Augmented reality for STEM learning: A systematic review. Computers \& Education, 123, 109-123. doi: https://doi.org/10.1016/j.compedu.2018.8.05.002 Google Scholar

HSU, T. Y., CHIOU, C. K., TSENG, J. C., y HWANG, G. J. (2016). Development and evaluation of an active learning support system for context-aware ubiquitous learning. IEEE Transactions on Learning Technologies, 9(1), 37-45. doi: $10.1109 / T L T .2015 .2439683$ Google Scholar

HUNG, P. H., HWANG, G. J., LEE, Y. H., WU, T. H., VOGEL, B., MILRAD, M., Y JOHANSSON, E. (2014). A problem-based ubiquitous learning approach to improving the questioning abilities of elementary school students. Journal of Educational Technology \& Society, 17(4), 316-334.

LEE, K. (2012). Augmented Reality in Education and Training. TechTrends, 56(2), 13-21. doi: https://doi.org/10.1007/s1 1528-012-0559-3. Google Schoiar

LEGUIA, M., y VIDAL, C. (1991). Rincones de actividad en la escuela infantil. Barcelona: Editorial Graó.

MANGELSDORF, M. (2008). Son buenos tiempos para la innovación disruptiva. Harvard Deusto Business Review, 181, 4-9.

MORENO, N., y LEIVA, J. (2017). Experiencias formativas de uso didáctico de la realidad aumentada con alumnado del grado de educación primaria en la universidad de Málaga. Edmetic, 6(1), 81-104. doi: https://doi.org/10.21071/edmetic.v6il.5809 Google Scholar

PIMMER, C., MATEESCU, M., y GRÖHBIEL, U. (2016). Mobile and ubiquitous learning in higher education settings. A systematic review of empirical studies. Computers in Human Behavior, 63, 490-501. doi: https://doi.org/10.1016/j.chb.2016.05.057 Google Scholar 
RIERA, M. A., FERRER, M., y RIBAS, C. (2018). La organización del espacio por ambientes de aprendizaje en la Educación Infantil: significados, antecedentes y reflexiones. RELAdEI, Revista Latinoamericana de Educación Infantil, 3(2), 19-39. Google Schojar

SENSAT, R. (2006). Materiales para la acción educativa. 'Rincón a rincón'. Actividades para trabajar con niños y niñas de 3- 8 años. Barcelona: Associacio de Mestres Rosa Sensat.

VILLALUSTRE, L. (2016). Educación Aumentada, una Realidad para favorecer el aprendizaje 3.0. CIREI 2016. 6-12 Junio. Madrid: Universidade Aberta (Portugal) y Universidad de Alcalá Henares (España).

WU, H. K., LEE, S. W. Y., CHANG, H. Y., y LIANG, J. C. (2013). Current status, opportunities and challenges of augmented reality in education. Computers \& Education, 62, 41-49. doi: https://doi.org/10.1016/j.compedu.2012.10.024 Google Scholar 